Article

\title{
Leaf Gas Exchange, Plant Water Relations and Water Use Efficiency of Vigna Unguiculata L. Walp. Inoculated with Rhizobia under Different Soil Water Regimes
}

\author{
Moussa Tankari ${ }^{1}$, Chao Wang ${ }^{1}$, Ximei Zhang ${ }^{1}, \operatorname{Li~Li~}^{1}$, Rajesh Kumar Soothar ${ }^{1}$, Haiyang Ma ${ }^{1,2}$, \\ Huanli Xing ${ }^{1}$, Changrong Yan ${ }^{1}$, Yanqing Zhang ${ }^{1}$, Fulai Liu ${ }^{3,4}$ and Yaosheng Wang ${ }^{1,4, *}$ \\ 1 State Engineering Laboratory of Efficient Water Use of Crops and Disaster Loss Mitigation/Key Laboratory \\ of Dryland Agriculture, Ministry of Agriculture and Rural Affairs of China, Institute of Environment and \\ Sustainable Development in Agriculture, Chinese Academy of Agricultural Sciences (CAAS), Beijing 100081, \\ China; tankarimoussa@yahoo.fr (M.T.); wangchao917@yeah.net (C.W.); zhangximei@caas.cn (X.Z.); \\ lilyleen2015@163.com (L.L.); rk_engr195@yahoo.com (R.K.S.); haiyangma2009@163.com (H.M.); \\ xinghuanli@163.com (H.X.); Yanchangrong@caas.cn (C.Y.); zhangyanqing@caas.cn (Y.Z.) \\ 2 South Subtropical Crops Research Institute, Chinese Academy of Tropical Agricultural Sciences, \\ Zhanjiang 524091, China \\ 3 Department of Plant and Environmental Sciences, University of Copenhagen, Højbakkegård Allé 13, \\ 2630 Taastrup, Denmark; fl@plen.ku.dk \\ 4 Key Laboratory of Agricultural Soil and Water Engineering in Arid and Semiarid Areas, \\ Ministry of Education of China, Northwest A \& F University, Yangling 712100, China \\ * Correspondence: wangyaosheng@caas.cn; Tel.: +86-10-82106794
}

Received: 23 January 2019; Accepted: 6 March 2019; Published: 9 March 2019

check for updates

\begin{abstract}
Impact of soil water regimes on physiological responses and water use efficiency (WUE) for Vigna unguiculata L. Walp. (cowpea) inoculated with rhizobia still remains implicit. Therefore, the goal of the current study was to examine the leaf gas exchange, abscisic acid (ABA) and hydraulic signaling, WUE and carbon and oxygen isotopic compositions $\left(\delta^{13} \mathrm{C}\right.$ and $\left.\delta^{18} \mathrm{O}\right)$ of cowpea under different soil water levels. The treatments included soil water regimes at three levels $(90 \%, 70 \%$, and $50 \%$ of soil water holding capacity (SWHC)) and two inoculation forms (inoculated and non-inoculated with rhizobia). The results showed that across the inoculation treatments, reduced soil water regimes depressed both stomatal conductance $\left(g_{s}\right)$ and photosynthesis $\left(A_{n}\right)$ of the leaves, nonetheless, the decrease of $g_{s}$ was more pronounced compared with the reduction in $A_{n}$. Consequently, the intrinsic water use efficiency $\left(\mathrm{WUE}_{\mathrm{i}}\right)$ was improved in the treatments under decreased soil water conditions. Plant WUE was also improved when soil water contents decreased as exemplified by the increased leaf $\delta^{13} \mathrm{C}$ and $\delta^{18} \mathrm{O}$, indicating the enhanced plant WUE was mainly attributed to the decrease of $\mathrm{g}_{\mathrm{s}}$. Significant interactions between soil water regimes and rhizobia treatments for root water potential (RWP), leaf water potential (LWP), and $\mathrm{g}_{\mathrm{s}}$ were found due to the different responses of rhizobia to varied soil water regimes. Inoculation could improve plant water status and $\mathrm{g}_{\mathrm{s}}$ under $70 \%$ and $90 \%$ SWHC compared to $50 \%$ SWHC with negative effect from rhizobia. A moderate soil water regime is suggested for cowpea production in terms of high WUE with a minor biomass reduction.
\end{abstract}

Keywords: abscisic acid; $\delta^{13} \mathrm{C} ; \delta^{18} \mathrm{O}$; rhizobium inoculation; stomata; water potential 


\section{Introduction}

Water deficit represents the most important restriction for biomass production in many tropical areas of developing countries [1]. Compared to other legumes, cowpea (Vigna unguiculata L. Walp.) is a vital food legume that has been cultivated successfully in tropical and sub-tropical regions where water is scarce [2,3]. It is a major source of dietary protein for humans as well as for animal feeding [4], and it can grow under limited water and high temperatures in low fertility soils. Further, it has the capacity to fix nitrogen which improves soil fertility. Therefore, it is considered as one of the important crops under future climate change scenarios where an increase in temperature and reduction in rainfall has been predicted in these regions [5]. Nowadays, cowpea is critical in saving the lives of people in Africa and other developing countries, as cowpea is the major crop for food security. However, in cowpea production most of the African farmers depend largely on natural rainfall, which is low and erratic, resulting in low and unstable yield [6]. Therefore, a better understanding of cowpea's responses to water stress is essential for improving yield and quality under future climate scenarios.

Stomata of leaves become partially closed in response to drought stress, which regulates the photosynthesis and transpiration rate and consequently modulates water use efficiency (WUE) $[7,8]$. Many studies on cowpea found that drought stress reduced photosynthesis $\left(A_{n}\right), g_{s}$ and transpiration [9-11]. It has been shown that drought stress increased endogenous abscisic acid (ABA) concentration in leaves of cowpea, which induces partial stomatal closure even at moderate soil water deficits [12-14]. In addition, hydraulic signals communicate the water status between root and shoot, regulating stomatal aperture, photosynthesis, and plant performance under limiting water availability [15]. Leaf or plant level WUE increases under moderate water stress [11,16-19], and this provides great potential for sustaining crop yield in drought-prone environments $[6,16,19]$. Increasing WUE at the leaf level means either to maintain stomatal conductance $\left(g_{s}\right)$ lower, which has more effect on transpiration than on photosynthesis, or to maintain high photosynthetic rate simultaneously with decreasing $g_{s}$ [20-22]. Reduced irrigation regimes, such as deficit irrigation, expose the plants to moderate drought stress, and this can induce chemical and/or hydraulic signaling, thereby, modulating $g_{s}$, hence, enhancing WUE $[15,23]$.

Rhizobia is a soil microorganism which is considered as one of the major symbiotic fixers of nitrogen [24]. Previous studies have demonstrated that rhizobia nodulation is affected by soil water regimes [25]. Jemo et al. [26] observed that the nodulation of cowpea was significantly decreased by water deficit at different soil phosphorus levels, presumably, due to the decreased infection and nodulation rates. Yanni et al. [27] reported that inoculation with tolerant rhizobia could increase the yield of seeds for the common bean in contrast to the non-inoculated plants under both well-watered and water-deficit treatments. Figueiredo et al. [28,29] and Bano et al [30] noticed that rhizobia could alleviate the drought stress for plants. However, the symbiotic efficiency was largely determined by rhizobium strains applied and soil conditions [26,28,31,32]. Hence, whether and how inoculation affects plant water status and leaf gas exchange in cowpea under varied soil water regimes is not well documented because of the uncertain inoculation effect in response to rhizobia inoculation to cowpea plants which have rarely been found to respond to inoculation [33]. Therefore, more researches are still necessary to illuminate the impact of soil water regimes on physiological responses for rhizobia inoculated cowpea.

Carbon isotopic composition $\left(\delta^{13} \mathrm{C}\right)$ of plants provides important information for long-term measurement of WUE [7,34], which is regulated by $A_{n}$ and/or $g_{s}$. Furthermore, oxygen isotopic composition $\left(\delta^{18} \mathrm{O}\right)$ of plants is influenced by $g_{s}$ but is not remarkably affected by $A_{n}$ [35]. The concurrent measurements of $\delta^{13} \mathrm{C}$ and $\delta^{18} \mathrm{O}$, therefore, can help to differentiate the relative significance of $A_{n}$ and $g_{s}$ on modulating WUE [35]. Therefore, the goal of the current study was to examine how soil water regimes affect plant physiological responses and WUE for rhizobia inoculated cowpea. 


\section{Materials and Methods}

\subsection{The Growing Conditions and Treatments}

The experiment was carried out between April and August 2017 in a temperature-controlled glasshouse at the Chinese Academy of Agricultural Sciences (CAAS), Beijing, China. The average temperatures in the day and night during the experimental period were 27 and $22{ }^{\circ} \mathrm{C}$, respectively, and the average air humidity was $70 \%$ during the experimental period. The photon flux density ranged from 450 to $800 \mu \mathrm{mol} \mathrm{m} \mathrm{m}^{-2} \mathrm{~s}^{-1}$. The experimental pots with a $16 \mathrm{~cm}$ diameter and $22 \mathrm{~cm}$ height and perforated holes at their basal parts were used. During the experimental period, leaching was not observed from the bottom of the pots. The soil was naturally dried and sieved by a $5 \mathrm{~mm}$ mesh, and then $6.72 \mathrm{~kg}$ of the soil was filled into each pot reaching a bulk density of $1.20 \mathrm{~g} \mathrm{dry} \mathrm{soil} \mathrm{cm}^{-3}$. The soil was sandy loam. The pot water-holding capacity of the soil was $35.0 \%$, and the permanent wilting point was $11.0 \%$. The soil had a $\mathrm{pH}$ of 7.6 , a total $\mathrm{N}$ of $1.0 \mathrm{~g} \mathrm{~kg}^{-1}$, and total $\mathrm{C}$ of $9.0 \mathrm{~g} \mathrm{~kg}^{-1}$. For each pot, an equal amount of $\mathrm{N}, \mathrm{P}$, and $\mathrm{K}$ fertilizers were mixed homogeneously into the soil at the rate of $2.85 \mathrm{~g} \mathrm{pot}^{-1}, 5.75 \mathrm{~g} \mathrm{pot}^{-1}$, and $1.88 \mathrm{~g} \mathrm{pot}^{-1}$ as $\mathrm{NH}_{4} \mathrm{NO}_{3}, \mathrm{KH}_{2} \mathrm{PO}_{4}$, and $\mathrm{K}_{2} \mathrm{SO}_{4}$, respectively, to meet the macronutrient demand during the growth period.

The treatments included three soil water regime levels $(90 \%, 70 \%$, and $50 \%$ of soil water holding capacity (SWHC), denoted as 90, 70 and 50, respectively) and two inoculation forms (inoculated and non- inoculated with rhizobia, designated as R and NR, respectively). The treatments with $90 \%$ of SWHC or NR were considered as control treatments for water and rhizobia inoculation treatments, respectively. The experiment was a completely randomized design with four replications for each treatment. The rhizobia (Bradyrhizobium japonicum, strain LXB0002) were provided by Leading Bio-agricultural CO., Ltd (Beijing, China). The seeds were supplied by the International Crops Research Institute for the Semi-Arid Tropics (ICRISAT). The seeds of cowpea (cultivar IT82E-18) were sterilized, and then the recommended dose of $150 \mathrm{~mL}$ of inoculants per $80 \mathrm{~kg}$ of seeds was applied to the seeds by mixing seeds homogenously with rhizobia. Three inoculated seeds were sown in each pot. Ten days after germination, plants in each pot were thinned to one plant. The plants in the pots were well irrigated, and twenty days after germination, the irrigation treatments were initiated. The soil water contents in the pots were measured daily (15:30-16:00 by using a time domain reflectometer (Soil Moisture Equipment Corp, Goleta, CA, USA). Two probes with the length of $15 \mathrm{~cm}$ were installed in each pot, and then the soil water contents were measured. The plants were irrigated daily between 16:00 to 17:00. Plant water use was computed by irrigation quantity, soil water contents measured, and the soil volume in the pots.

\subsection{Sampling, Measurements and Analyses}

The stomatal conductance $\left(g_{s}\right)$, evapotranspiration $(E)$ and photosynthetic rate $\left(A_{n}\right)$ were measured weekly with photosynthetically active radiation at $1800 \mu \mathrm{mol} \mathrm{m}^{-2} \mathrm{~s}^{-1}$ with Li-6400 Portable Photosynthesis System (Li-Cor Biosciences, Lincoln, NE, USA) from 9:00 to 11:00 am on upper fully expanded leaves of plants. Sixty-one days after initiation of the irrigation treatment, the plants were harvested. The sampling and measurements of roots and leaves for ABA concentration ([ABA] root and $[\mathrm{ABA}]_{\text {leaf }}$ ), root and leaf water potential (RWP and LWP) as well as carbon and oxygen isotopic compositions $\left(\delta^{13} \mathrm{C}\right.$ and $\left.\delta^{18} \mathrm{O}\right)$ followed the procedures described in Wang et al. [36]. The area of leaves was determined by using a leaf area meter (model 3050A, Li-Cor Biosciences, Lincoln, NE, USA). The dry weight of biomass samples was measured at $70{ }^{\circ} \mathrm{C}$ in the oven to constant weight. The water use efficiency (WUE) of plants was computed as above-ground dry weight/plant water use. Intrinsic water use efficiency $\left(\mathrm{WUE}_{\mathrm{i}}\right)$ was determined as $\mathrm{A}_{\mathrm{n}} / \mathrm{g}_{\mathrm{s}}$.

\subsection{Statistical Analysis}

The data were firstly evaluated by Homogeneity test, and all the data followed the normal distribution. Therefore, they were not transformed and were analyzed by two-way analysis of 
variance (ANOVA) with SPSS 23.0 software (IBM Corporation, New York, NY, USA). Differences between treatments were tested when the value was less than 0.05 by Ducan's multiple range test. The significances for each experimental factor as well as the interactions between treatments were obtained. Linear regression was deployed to determine the correlations between the parameters determined by using SPSS 23.0 software (IBM Corporation, New York, NY, USA).

\section{Results}

\subsection{Soil Water Changes}

Daily average soil water contents differed significantly among the water treatments (Figure 1). In the treatment with high soil water content, soil water contents remained around $24 \%$ during the treatment period. Soil water contents were kept around $19 \%$ and $14 \%$ in the treatments with medium and low soil water levels, respectively. The treatments with or without rhizobia inoculation had similar soil water contents.

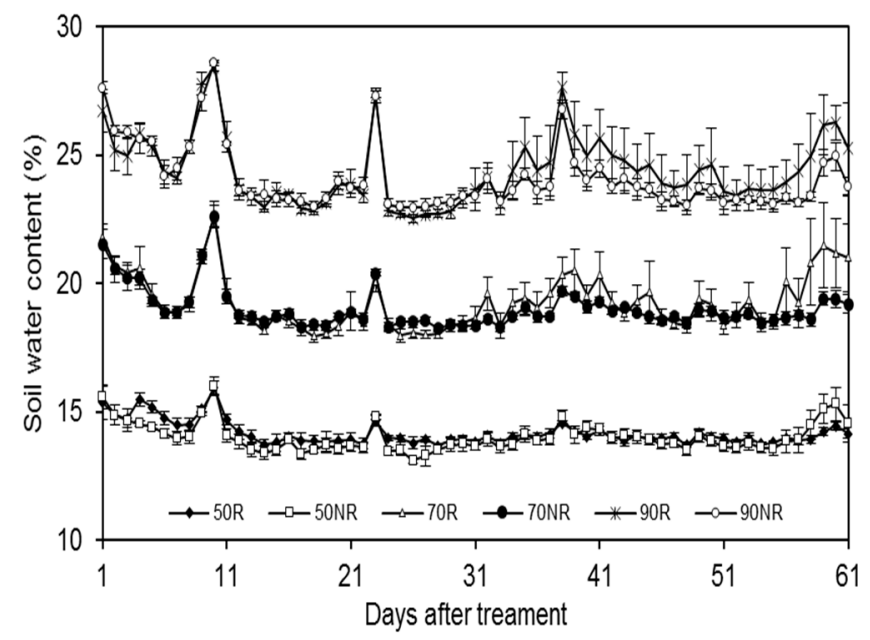

Figure 1. Changes of daily average soil water contents in the pots under the soil water levels at $90 \%$, $70 \%$, and $50 \%$ of soil water holding capacity (SWHC) and rhizobia inoculation (with rhizobia (R) and without rhizobia (NR)). Values are means \pm standard error $(\mathrm{SE})(\mathrm{n}=4)$.

\subsection{Leaf Gas Exchange}

The analysis across soil water treatments showed that the leaf gas exchange was not affected by rhizobia inoculation (Figure 2), while soil water regimes significantly influenced the averaged $A_{n}$, $\mathrm{g}_{\mathrm{s}}$, and $\mathrm{WUE}_{\mathrm{i}}$ across the inoculation treatments. The treatment with high soil water content had the highest $A_{n}$ and $g_{s}$, followed by the treatments with medium and low soil water contents. Consequently, the $W_{U E}$ increased under the treatments with low and medium soil water levels in comparison with high soil water treatment. The significant interaction between water level and inoculation was found for $g_{s}$ (Figure 2). 


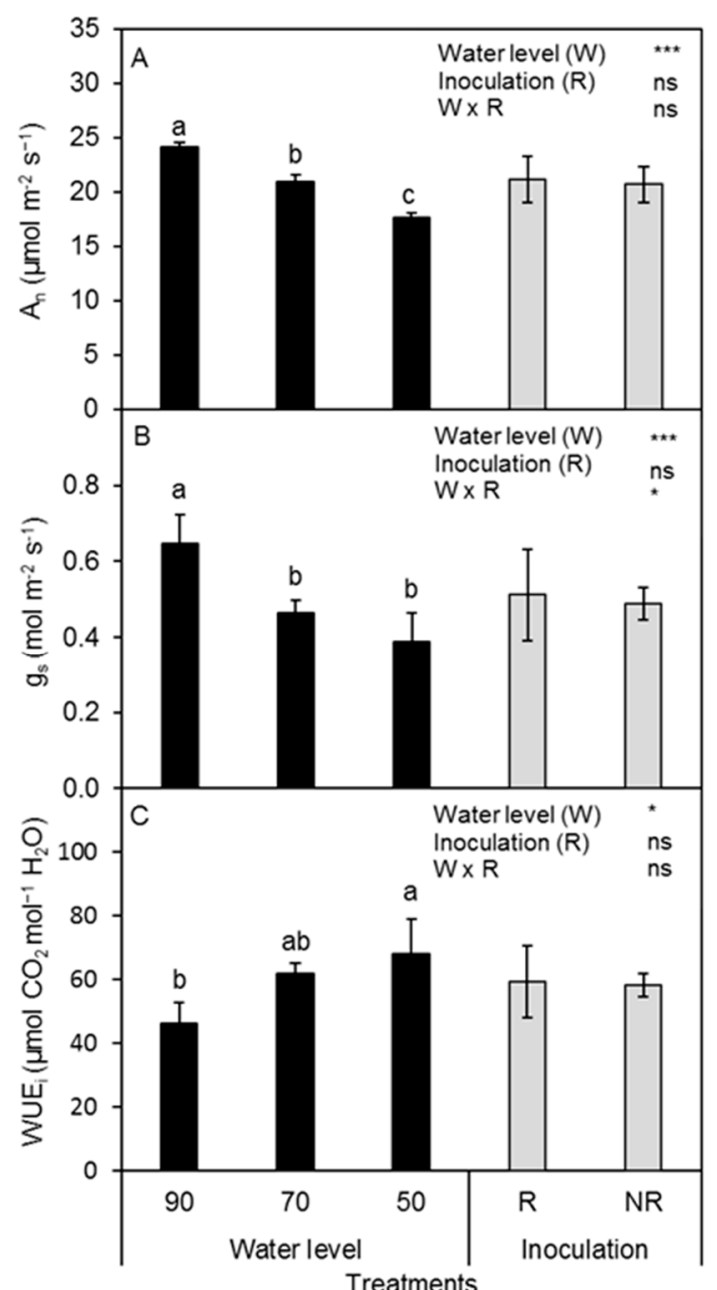

Figure 2. Effect of soil water regimes and rhizobia inoculation on $(\mathbf{A})$ averaged photosynthesis $\left(A_{n}\right)$, (B) stomatal conductance $\left(g_{s}\right)$, and $(C)$ intrinsic water use efficiency $\left(W_{U E}\right)$ of cowpea during the experimental period. 50, 70 and 90 denote $50 \%, 70 \%$, and $90 \%$ of SWHC. R and NR indicate inoculation with and without rhizobia. Values are means \pm SE $(n=8$ for $90 \%, 70 \%$ and $50 \%$ of SWHC treatments and $\mathrm{n}=12$ for $\mathrm{R}$ and NR treatments). Different letters indicate significant differences in the experimental factor at $p<0.05$ according to Duncan's multiple range test.

\subsection{Leaf Area and Root Nodule Number}

Across the inoculation treatments, leaf area decreased significantly with the reduced soil water contents (Figure 3). The high soil water treatment had the highest leaf area, intermediate under treatment with medium soil water content, and lowest under treatment with low soil water content. Nevertheless, leaf area was not affected by inoculation treatment. The number of root nodules was increased by $36 \%$ when plants were inoculated with rhizobia, though the root nodule number was not statistically different between the inoculation treatments across the soil water levels. 


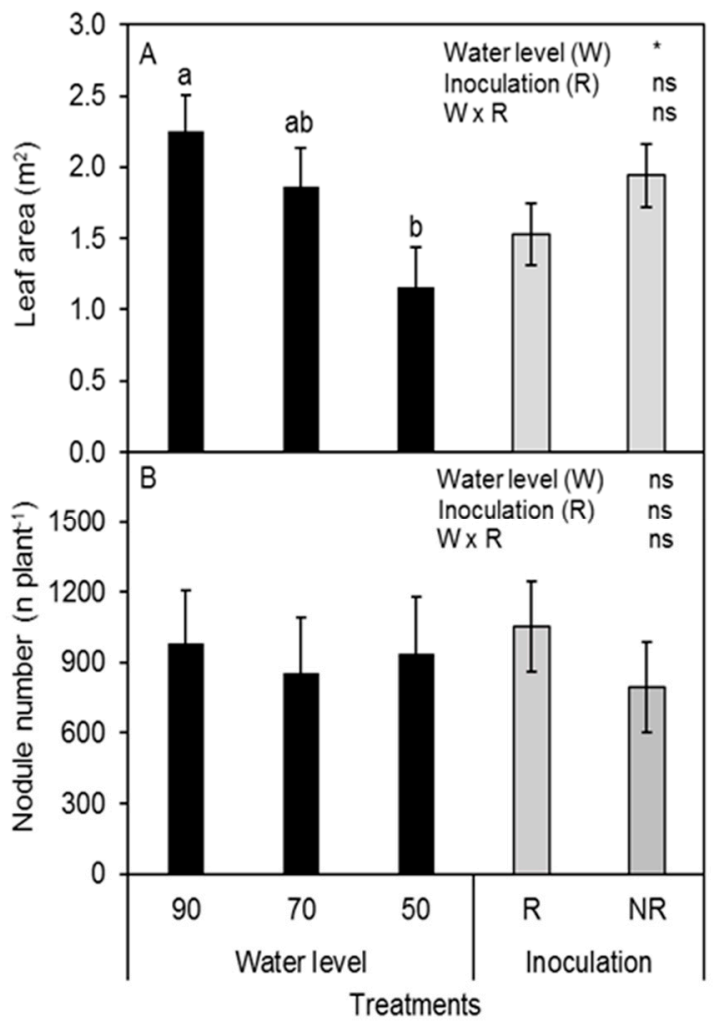

Figure 3. (A) Leaf area and (B) root nodule number of cowpea under different soil water regimes $(90 \%$, $70 \%$, and $50 \%$ of SWHC) and rhizobia inoculation. Values are means + SE ( $\mathrm{n}=8$ for $90 \%, 70 \%$, and $50 \%$ of SWHC treatments and $\mathrm{n}=12$ for R and NR treatments). Different letters indicate significant differences in the experimental factor at $p<0.05$ according to Duncan's multiple range test.

\subsection{Plant Water Status and ABA Concentration}

When analyzed across the inoculation treatments, LWP was similar under different soil water regimes whereas RWP was significantly decreased under the water-stressed treatments (Figure 4). Rhizobia inoculation had no significant effect on LWP and RWP. However, the interactions between water level and rhizobia treatment for LWP and RWP were significant (Figure 4). [ABA] $]_{\text {root }}$ and $[\mathrm{ABA}]_{\text {leaf }}$ were similar among the soil water treatments or between the inoculation treatments (Figure 5). 


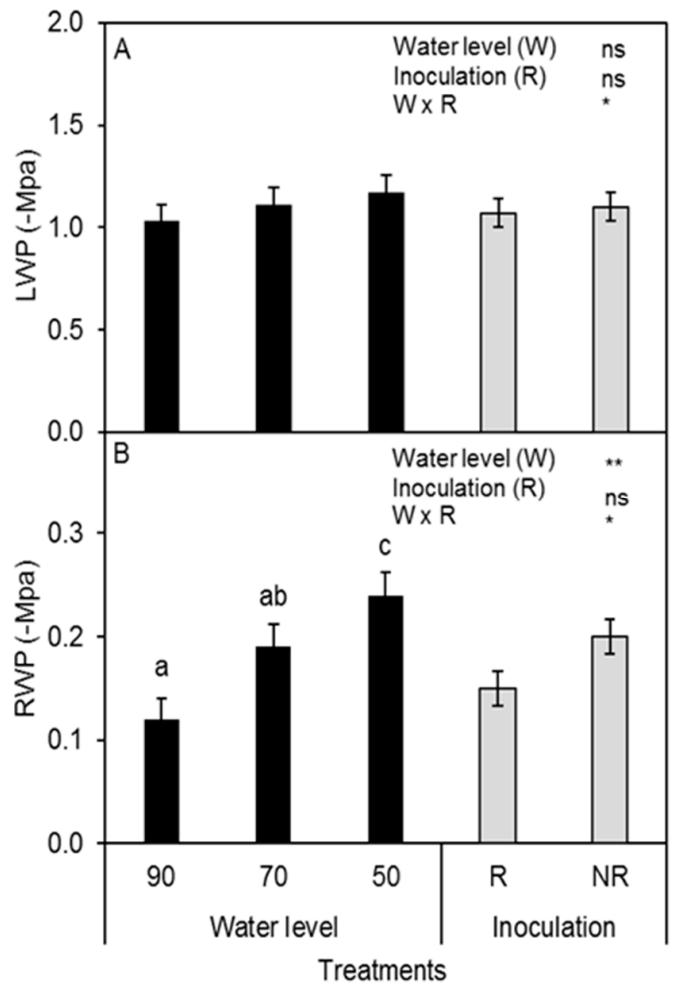

Figure 4. (A) Leaf water potential (LWP) and (B) root water potential (RWP) of cowpea under different soil water regimes $(90 \%, 70 \%$, and $50 \%$ of SWHC) and rhizobia inoculation. Values are means + SE ( $\mathrm{n}=8$ for $90 \%, 70 \%$, and $50 \%$ of SWHC treatments and $\mathrm{n}=12$ for R and NR treatments). Different letters indicate significant differences in the experimental factor at $p<0.05$ according to Duncan's multiple range test.

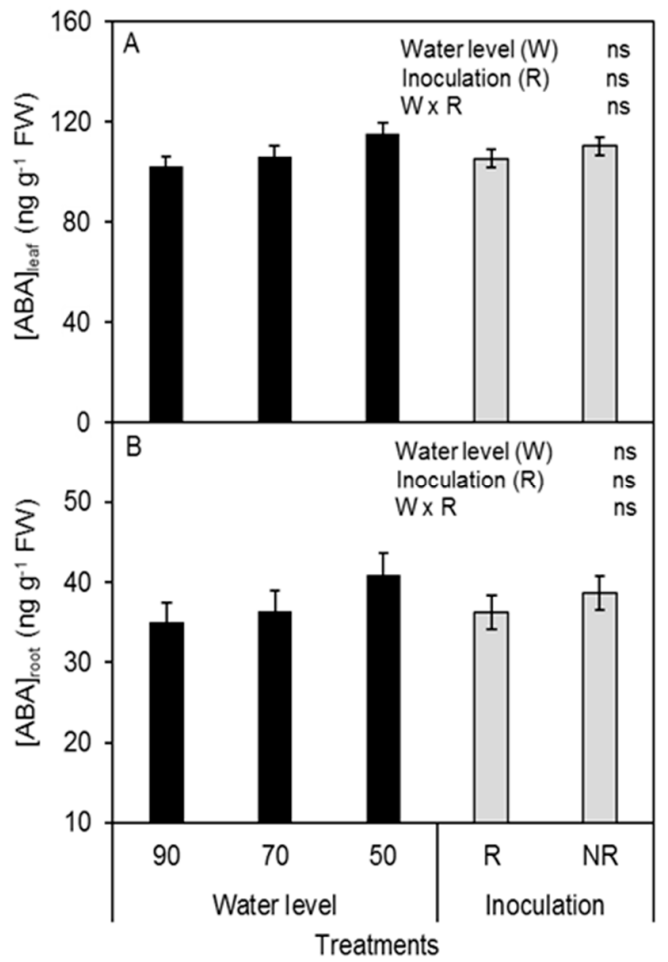

Figure 5. (A) Leaf abscisic acid and (B) root abscisic acid (ABA) concentration of cowpea under different soil water regimes $(90 \%, 70 \%$, and $50 \%$ of SWHC) and rhizobia inoculation. Values are means + SE ( $\mathrm{n}=8$ for $90 \%, 70 \%$, and $50 \%$ of SWHC treatments and $\mathrm{n}=12$ for R and NR treatments). 


\subsection{Biomass Accumulation, Plant Water Use, Water Use Efficiency, Plant $\delta^{13} \mathrm{C}$ and $\delta^{18} \mathrm{O}$}

Across the inoculation treatments, the above-ground dry biomass, plant water use, and WUE differed significantly among the soil water regimes, while they were similar between the inoculation treatments (Table 1). Plants under medium and low soil water treatments consumed significantly less water compared with the well-watered treatment. The biomass accumulation was significantly decreased in the low soil water treatments compared to the medium and high soil water treatments. The treatments with medium and low soil water contents had significantly higher plant WUE than that in the treatment with high soil water content. The low soil water treatment had the highest plant $\delta^{13} \mathrm{C}$ and $\delta^{18} \mathrm{O}$, intermediate under treatment with medium soil water content, and lowest under treatment with low soil water condition. WUE $\mathrm{i}_{\mathrm{i}}$ was significantly positively correlated with leaf $\delta^{13} \mathrm{C}$ (Figure 6). Furthermore, significant positive linear relationships between plant $\delta^{18} \mathrm{O}$ and $\mathrm{g}_{\mathrm{s}}$, between plant $\delta^{18} \mathrm{O}$ and $\mathrm{E}$, and also between plant $\delta^{18} \mathrm{O}$ and $\delta^{13} \mathrm{C}$ were observed.

Table 1. Effect of soil water regimes, rhizobia inoculation and their interactions on biomass accumulation, plant water use, water use efficiency (WUE), plant carbon and oxygen isotopic compositions $\left(\delta^{13} \mathrm{C}\right.$ and $\left.\delta^{18} \mathrm{O}\right)$ of cowpea under different soil water regimes $(90 \%, 70 \%$, and $50 \%$ of soil water holding capacity (SWHC)) and rhizobia inoculation. Values are means \pm SE ( $\mathrm{n}=8$ for $90 \%, 70 \%$, and $50 \%$ of SWHC treatments and $\mathrm{n}=12$ for inoculated and non- inoculated (R and NR) treatments). Means with different letters indicate significant differences and ns denotes not significant at $p<0.05$ according to Duncan's multiple range test.

\begin{tabular}{|c|c|c|c|c|c|}
\hline Factors & $\begin{array}{l}\text { Above-Ground } \\
\text { Dry Biomass } \\
\left.\text { (g plant }^{-1}\right)\end{array}$ & $\begin{array}{c}\text { Plant Water } \\
\text { Use } \\
\left.\text { (L plant }^{-1}\right)\end{array}$ & $\begin{array}{c}\text { WUE } \\
\left(\mathrm{g} \mathrm{L}^{-1}\right)\end{array}$ & $\begin{array}{c}\text { Plant } \delta^{13} \mathrm{C} \\
(\%)\end{array}$ & $\begin{array}{c}\text { Plant } \delta^{18} \mathrm{O} \\
(\%)\end{array}$ \\
\hline \multicolumn{6}{|c|}{ Water level } \\
\hline 90 & $162.9 \pm 10.1 \mathrm{a}$ & $48.1 \pm 2.1 \mathrm{a}$ & $3.4 \pm 0.1 b$ & $-27.41 \pm 0.16 b$ & $26.89 \pm 0.27 b$ \\
\hline 70 & $138.5 \pm 8.2 \mathrm{a}$ & $36.4 \pm 1.5 \mathrm{~b}$ & $3.8 \pm 0.1 \mathrm{a}$ & $-26.67 \pm 0.15 a$ & $27.38 \pm 0.29 \mathrm{ab}$ \\
\hline 50 & $80.9 \pm 2.6 b$ & $22.7 \pm 0.9 c$ & $3.6 \pm 0.1 \mathrm{ab}$ & $-26.50 \pm 0.32 \mathrm{a}$ & $27.86 \pm 0.10 \mathrm{a}$ \\
\hline Significance & $* * *$ & $* * *$ & * & $*$ & * \\
\hline \multicolumn{6}{|c|}{ Inoculation } \\
\hline $\mathrm{R}$ & $123.0 \pm 13.0$ & $34.8 \pm 3.6$ & $3.5 \pm 0.1$ & $-27.03 \pm 0.23$ & $27.21 \pm 0.25$ \\
\hline NR & $135.0 \pm 11.9$ & $37.8 \pm 3.4$ & $3.6 \pm 0.1$ & $-26.74 \pm 0.17$ & $27.50 \pm 0.18$ \\
\hline Significance & ns & ns & ns & ns & ns \\
\hline \multicolumn{6}{|c|}{ Water level x Inoculation } \\
\hline Significance & ns & ns & ns & ns & ns \\
\hline
\end{tabular}



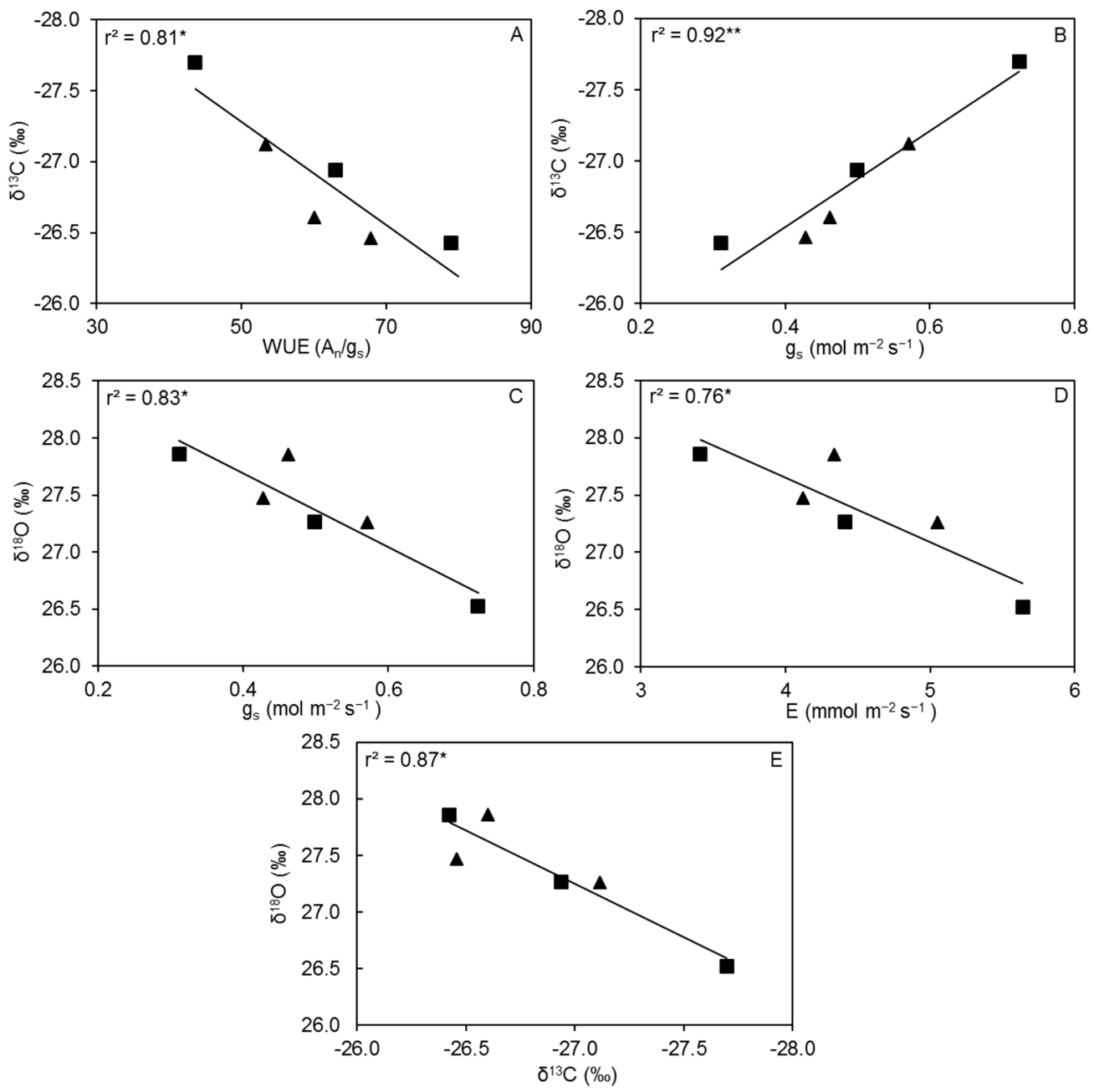

Figure 6. Relationships between (A) plant $\delta^{13} \mathrm{C}$ and $\mathrm{WUE}_{\mathrm{i}},(\mathbf{B})$ plant oxygen isotopic composition $\left(\delta^{13} \mathrm{C}\right)$ and $g_{s},(C)$ plant oxygen isotopic composition $\left(\delta^{18} \mathrm{O}\right)$ and $g_{s},(\mathbf{D})$ plant $\delta^{18} \mathrm{O}$ and E, (E) plant carbon isotopic composition $\left(\delta^{13} \mathrm{C}\right)$ and $\delta^{18} \mathrm{O}$ under soil water and inoculation treatments. The solid squares and triangles denote the data points in the inoculated and non-inoculated treatment, respectively.

* indicates the significance at $p<0.05$, while ** denotes the significance of regression line at $p<0.01$.

\section{Discussion}

Increasing WUE is becoming crucial in improving crop productivity under water stress conditions. When analyzed across the inoculation treatments, soil water regimes showed a significant effect on leaf gas exchange and WUE at the leaf level $\left(W_{U} E_{i}\right)\left(\right.$ Figure 2). The $A_{n}$ and $g_{s}$ decreased with the reduction of soil water regimes. $W_{U E}$ increases when a reduction in $g_{s}$ is more prominent than in $A_{n}$ [37]. The results showed that $g_{s}$ was impaired more significantly than the $A_{n}$ by the partial closure of stomata under deficit soil water conditions. Consequently, medium and low water treatments increased $W_{U E}$ compared with high soil water treatment. This indicates that the significant reduction in $g_{s}$ was primarily responsible for the increase of $W_{U E}$ in the treatments with medium and low soil water regimes. A decrease in $A_{n}$ and $g_{s}$ under water deficit was previously observed in cowpea plants when irrigation was maintain lower than $70 \%$ of soil water holding capacity $[9-11,17,38]$. The severe water stress in the low water treatment inhibited physiological activities, and consequently, led to decreased leaf biomass growth $[23,39,40]$. For the medium soil water treatment, RWP, leaf area, and biomass growth were also depressed to some extent. However, they were not decreased significantly when compared with those under the high soil water regime. Chemical and/or hydraulic signaling can play crucial functions during water stress, such as they act on stomatal regulation 
and transpiration [23,41-43]. Previous studies have reported increased leaf ABA concentration in cowpea plants under water stress after withholding water or at soil water content between $20 \%$ and $30 \%[3,13,44]$. Similarly, Luchi et al. [12] also reported that water stress imposed by withholding water for one month resulted in a significant increase of $[\mathrm{ABA}]_{\text {leaf }}$ in cowpea plants. However, in the present study, similar $[\mathrm{ABA}]_{\text {leaf }}$ and $[\mathrm{ABA}]_{\text {root }}$ were found under different soil water regimes, though an increase in $[\mathrm{ABA}]_{\text {leaf }}$ and $[\mathrm{ABA}]_{\text {root }}$ by $18 \%$ and $17 \%$ was observed in the treatment with low soil water content in comparison with the high soil water regime. In the current study, reduced soil water regimes significantly reduced RWP, which could decrease leaf expansion and $\mathrm{g}_{\mathrm{s}}$ in the deficit water treatments. Previous studies documented that cowpea plants could maintain leaf water status to overcome limited water supply as exemplified by an insignificant change in LWP after withholding water [38]. In the current study, LWP was sustained under the water-stressed treatments compared to the high water treatment. This indicated that when the cowpea plants were under water-stressed conditions, they quickly adapted to such conditions via decreasing leaf expansion and stomatal opening, thus, the leaf water status was maintained compared with well-watered plants. Likewise, Verbree et al. [45] found that cowpea did not show any significant differences in LWP after three weeks of withholding irrigation. It is noteworthy that, inoculation with rhizobia did not show a significant effect on plant physiological activities across the soil water treatments, however, significant interactions between soil water regimes and rhizobia treatments were observed for LWP, RWP, and $g_{s}$. This indicated that the impact of rhizobia on LWP, RWP, and $g_{s}$ was dependent on the specific soil water regimes. The results showed that under the treatments with $70 \%$ and $90 \%$ SWHC, rhizobia inoculation increased RWP, LWP, and $\mathrm{g}_{\mathrm{s}}$, however, under treatment with $50 \% \mathrm{SWHC}$, inoculation with rhizobia showed a negative effect on plant water status and stomatal opening (data not shown). Similarly, Tairo et al. [46] reported a significant interaction between water stress and rhizobia in common bean (P. vulgaris) and noticed that applying rhizobia inoculation and stressing plants with water enhanced plant growth and seed yield. In future studies, the interactions between soil water regimes and rhizobia merit further investigation.

Previous studies in cowpea showed an increase of WUE at the whole plant level under limited water supply [47]. In the present study, plants under the medium and low water treatments improved WUE by $12 \%$ and $6 \%$ compared with the treatment with high soil water content. However, other studies observed decreases in WUE in some cowpea varieties when soil water potential was maintained at $-75 \mathrm{kPa}$ [9]. This variation of WUE under limited water supply may be due to the differences in the cultivar used, the intensity of the stress imposed, and the environmental conditions [48]. To explore further how the WUE were regulated by leaf gas exchange during the treatment period as affected by different soil water regimes, carbon and oxygen isotopic composition were determined as long-term time-integrated measurements. Many studies have shown that water stress increases $\delta^{13} \mathrm{C}$ in plant biomass $[6,18,49]$. In good agreement with this, a significant increase of $\delta^{13} \mathrm{C}$ value was observed in the plants under low and medium water treatments together with improved WUE in these two treatments compared to the high water treatment (Table 1). Previous studies have reported a positive correlation between plant $\delta^{13} \mathrm{C}$ and WUE [21,50-52]. The results showed that plant $\delta^{13} \mathrm{C}$ was positively and linearly correlated with $W_{U E}$. The difference in plant $\delta^{13} \mathrm{C}$ is caused by either variation in $\mathrm{g}_{\mathrm{s}}$ or $A_{n}$, or both [34,53]. As mentioned above, in the current study, both $g_{s}$ and $A_{n}$ were decreased in the treatments with reduced soil water regimes. However, $g_{s}$ decreased more pronouncedly compared with the reduction in $A_{n}$ in these treatments. To further differentiate the impact of these two factors on modulating WUE, oxygen isotopic composition $\left(\delta^{18} \mathrm{O}\right)$ was determined in the present study to indicate time-integrated measurement of $g_{s}$ during the treatment period, as plant $\delta^{18} \mathrm{O}$ is mainly influenced by changes in $g_{s}$ and transpiration in comparison with variations in $A_{n}$. Hence, plant $\delta^{18} \mathrm{O}$ can be used to differentiate whether differences in $\delta^{13} \mathrm{C}$ are mainly a result of variations in $\mathrm{g}_{\mathrm{s}}$ or $A_{n}[34,42,54,55]$. As expected, the medium and low soil water treatments increased $\delta^{18} \mathrm{O}$ values by $3 \%$ and $4 \%$, respectively, when compared with those under the high soil water regime. Significant negative linear relationships were found between plant $\delta^{18} \mathrm{O}$ and $g_{\mathrm{s}}$ as well as between plant $\delta^{18} \mathrm{O}$ and $\mathrm{E}$ (Figure 6). It is said that when $\mathrm{g}_{\mathrm{s}}$ determines the variations of $\delta^{13} \mathrm{C}$, a positive relationship between 
$\delta^{18} \mathrm{O}$ and $\delta^{13} \mathrm{C}$ should exist [54-58], which was found in our study (Figure 6). This indicates that the increased $\delta^{13} \mathrm{C}$ and WUE in the treatments with decreased soil water regimes were mainly attributed to the reduced $\mathrm{g}_{\mathrm{s}}$.

Nodulation was not significantly affected by soil water regimes or rhizobia inoculation, though plant inoculated with rhizobia increased their nodule number compared to those non-inoculated. Consequently, inoculation showed minimal relation with plant growth and physiological responses. Similar results have been reported in previous studies in cowpea but not in conditions of water stress $[59,60]$. They studied the effect of rhizobia inoculation in different soil types under well-watered condition and concluded that rhizobia were ineffective to improve biomass production and the number of nodules. Ulzen et al. [61] reported contrasting responses of rhizobia inoculation in two sites inoculated even with the same strains under rainfall condition and concluded that the non-response of rhizobia at Nyagli site was due to the lower native number of strains and other unknown factors. Furthermore, some previous studies found that cowpea inoculated with two glums species did not significantly affect leaf gas exchange under the volumetric soil water content around 8\% [62]. Similarly, the ineffectiveness of rhizobia was also reported in soybean [63,64]. Nonetheless, Figueiredo et al. [65] noted that water deficit significantly decreased nodule number and weight for cowpea at more negative soil water potential lower than $-60 \mathrm{kPa}$. Likewise, Mouradi et al. [32] reported that water stress level at $40 \%$ of SWHC significantly reduced the number and dry weight of nodules for alfalfa. In the above-mentioned studies, it is noteworthy that the symbiotic efficiency varied according to specific rhizobium strains in response to soil water regimes. Catroux et al. [66] reported that the effectiveness of inoculants is largely determined by the rhizobia available to effectively be involved in the process of infection in the soil after application. It appears that the efficiency of rhizobium strains is largely dependent upon the tolerance of rhizobia and the varied soil environments which cause the discrepancies for the results in the above-mentioned studies. In the present study, the strain of the rhizobia might not be tolerant to water stress, or the symbiotic effectiveness of the inoculation might be negatively affected by water deficit, leading to the trivial impact of rhizobia inoculation on plants. Therefore, more researches are still needed to further examine plant WUE as regulated synchronously by soil water contents and inoculation with varied strains of rhizobia. Importantly, before the application of rhizobium strains in the field, investigations should be made to examine the inoculation efficiency of rhizobium strains and their relations with soil environments for specific crops.

\section{Conclusions}

Reduction in soil water regimes decreased stomatal conductance $\left(\mathrm{g}_{\mathrm{s}}\right)$, and depressed photosynthesis rate $\left(A_{n}\right)$, nonetheless, $g_{s}$ decreased more pronouncedly compared with the reduction in $A_{n}$ regulated mainly by hydraulic signals for cowpea inoculated with rhizobia. In consequence, $W_{U} E_{i}$ was improved under reduced soil water regimes. Plant $\delta^{13} C$ and WUE increased significantly under the medium and low water treatments. Leaf $\delta^{18} \mathrm{O}$ indicated that the increase of leaf $\delta^{13} \mathrm{C}$ and WUE in the condition with decreased soil water contents were principally ascribed to the decrease of $\mathrm{g}_{\mathrm{s}}$. Moderate soil water content is suggested for cowpea production in terms of high WUE with mild biomass reduction. When rhizobia are used for crop production, it is suggested that the effectiveness and benefit of strains are tested in specific locations even in the same growing zone.

Author Contributions: Y.W. designed the experiment. M.T. conducted the experiment with C.W., L.L., R.K.S. and H.M. M.T. and C.W. processed and analyzed the data. M.T. drafted the manuscript. Y.W. and F.L. revised the manuscript. H.X., X.Z., C.Y. and Y.Z. assisted with the experiment. All the authors reviewed the manuscript and approved the content of this manuscript.

Funding: This research was funded by the National Key Research and Development Program of China (grant no. 2018YFGH000241), the Central Public Interest Institution Basal Research Fund (grant no. BSRF201710), the Agricultural Science and Technology Innovation Program and the Elite Youth Program of Chinese Academy of Agricultural Sciences. Moussa Tankari appreciates the Chinese Government Scholarship for supporting his study at the Chinese Academy of Agricultural Sciences.

Conflicts of Interest: The authors declare no conflict of interest. 


\section{References}

1. Donohue, R.J.; Roderick, M.L.; McVicar, T.R.; Farquhar, G.D. Impact of $\mathrm{CO}_{2}$ fertilization on maximum foliage cover across the globe's warm, arid environments. Geophys. Res. Lett. 2013, 40, 3031-3035. [CrossRef]

2. Ehlers, J.D.; Hall, A.E. Cowpea (Vigna unguiculata L. Walp.). Field Crops Res. 1997, 53, 187-204. [CrossRef]

3. Scotti-Camposbr, P.; PhamThibr, A.; Semedobr, J.; Paisbr, I.; Matos, J. Physiological responses and membrane integrity in three Vigna genotypes with contrasting drought tolerance. Emir. J. Food Agric. 2013, $23,1002$. [CrossRef]

4. Da Silva, D.O.M.; Santos, C.A.F.; Boiteux, L.S. Adaptability and stability parameters of total seed yield and protein content in cowpea (Vigna unguiculata L. Walp.) genotypes subjected to semi-arid conditions. Aust. J. Crop Sci. 2016, 10, 1164-1169. [CrossRef]

5. Carvalho, M.; Muñoz-amatriaín, M.; Castro, I.; Lino-neto, T.; Matos, M.; Egea-cortines, M.; Rosa, E.; Close, T.; Carnide, V. Genetic diversity and structure of Iberian Peninsula cowpeas compared to world-wide cowpea accessions using high density SNP markers. BMC Genom. 2017, 18, 891. [CrossRef] [PubMed]

6. Makoi, J.H.J.R.; Chimphango, S.B.M.; Dakora, F.D. Photosynthesis, water-use efficiency and $813 \mathrm{C}$ of five cowpea genotypes grown in mixed culture and at different densities with sorghum. Photosynthetica 2010, 48, 143-155. [CrossRef]

7. Farquhar, G.D.; Ehleringer, J.R.; Hubick, K.T. Carbon isotope discrimination and photosynthesis. Ann. Rev. Plant Physiol. Plant Mol. Biol. 1989, 40, 503-537. [CrossRef]

8. Yoo, C.; Pence, H.E.; Hasegawa, P.M.; Mickelbart, M.V. Regulation of transpiration of improving crop water use. Crit. Rev. Plant Sci. 2009, 28, 410-431. [CrossRef]

9. Anyia, A.O.; Herzog, H. Water-use efficiency, leaf area and leaf gas exchange of cowpeas under mid-season drought. Eur. J. Agron. 2004, 20, 327339. [CrossRef]

10. Verbree, D.A.; Singh, B.B.; Payne, W.A. Genetics and heritability of shoot drought tolerance in cowpea seedlings. Crop Sci. 2015, 55, 146-153. [CrossRef]

11. Han, J.M.; Meng, H.F.; Wang, S.Y.; Jiang, C.D.; Liu, F.; Zhang, W.F.; Zhang, Y.L. Variability of mesophyll conductance and its relationship with water use efficiency in cotton leaves under drought pretreatment. J. Plant Physiol. 2016, 194, 61-71. [CrossRef] [PubMed]

12. Luchi, S.; Kobayashi, M.; Yamaguchi-Shinozaki, K.; Shinozaki, K. A stress-inducible gene for 9-cis-Epoxycarotenoid dioxygenase involved in abscisic acid biosynthesis under water stress in drought-tolerant cowpea. Plant Physiol. 2000, 123, 553-562. [CrossRef]

13. Luchi, S.; Yamaguchi-Shinozaki, K.; Urao, T.; Terao, T.; Shinozaki, K. Novel drought-inducible genes in the highly drought-tolerant cowpea: Cloning of cDNAs and analysis of their gene expression. Plant Cell Physiol. 1996, 37, 1073-1082. [CrossRef]

14. Nolan, R.H.; Tarin, T.; Santini, N.S.; McAdam, S.A.M.; Ruman, R.; Eamus, D. Differences in osmotic adjustment, foliar abscisic acid dynamics, and stomatal regulation between an isohydric and anisohydric woody angiosperm during drought. Plant Cell Environ. 2017, 40, 3122-3134. [CrossRef]

15. Christmann, A.; Weiler, E.W.; Steudle, E.; Grill, E. A hydraulic signal in root-to-shoot signalling of water shortage. Plant J. 2007, 52, 167-174. [CrossRef] [PubMed]

16. Liu, F.; Jensen, C.R.; Shahanzari, A.; Andersen, M.N.; Jacobsen, S.E. ABA regulated stomatal control and photosynthetic water use efficiency of potato (Solanum tuberosum L.) during progressive soil drying. Plant Sci. 2005, 168, 831-836. [CrossRef]

17. Singh, S.K.; Reddy, R.K. Regulation of photosynthesis, fluorescence, stomatal conductance and water-use efficiency of cowpea (Vigna unguiculata L. Walp.) under drought. J. Photochem. Photobiol. B Biol. 2011, 105, 40-50. [CrossRef]

18. Munjonji, L.; Ayisi, K.K.; Vandewalle, B.; Haesaert, G.; Boeckx, P. Combining carbon-13 and oxygen-18 to unravel triticale grain yield and physiological response to water stress. Field Crop. Res. 2016, 195, 36-49. [CrossRef]

19. Pazzagli, P.T.; Weiner, J.; Liu, F. Effects of $\mathrm{CO}_{2}$ elevation and irrigation regimes on leaf gas exchange, plant water relations, and water use efficiency of two tomato cultivars. Agric. Water Manag. 2016, 169, $26-33$. [CrossRef]

20. Farquhar, G.D.; Sharkey, T.D. Stomatal conductance and photosynthesis. Ann. Rev. Plant Physiol. 1982, 33, 317-345. [CrossRef] 
21. Jones, H.G. Plants and Microclimate: A Quantitative Approach to Environmental Plant Physiology, 2nd ed.; Cambridge University Press: Cambridge, UK, 1992.

22. Wang, Y.; Liu, F.; Andersen, M.N.; Jensen, C.R. Improved plant nitrogen nutrition contributes to higher water use efficiency in tomatoes under alternate partial root-zone irrigation. Funct. Plant Biol. 2010, 37, 175-182. [CrossRef]

23. Chaves, M.M.; Oliveira, M.M. Mechanisms underlying plant resilience to water deficits: Prospects for water-saving agriculture. J. Exp. Bot. 2004, 55, 2365-2384. [CrossRef] [PubMed]

24. Herridge, D.F.; Herridge, D. Managing Legume and Fertiliser N for Northern Grains Cropping, 2nd ed.; The GRDC and the University of New England: Armidale, NSW, Australia, 2013.

25. Serraj, R.; Sinclair, T.R.; Purcell, L.C. Symbiotic N2 fixation response to drought. J. Exp. Bot. 1999, 50, $143-155$. [CrossRef]

26. Jemo, M.; Sulieman, S.; Bekkaoui, F.; Olomide, O.A.K.; Hashem, A.; Abd-Allah, E.F.; Alqarawi, A.A.; Tran, L.P. Comparative Analysis of the Combined Effects of Different Water and Phosphate Levels on Growth and Biological Nitrogen Fixation of Nine Cowpea. Front. Plant Sci. 2017, 8, 2111. [CrossRef] [PubMed]

27. Yanni, Y.; Zidan, M.; Dazzo, F.; Rizk, R.; Mehesen, A.; Abdelfattah, F.; Elsadany, A. Enhanced symbiotic performance and productivity of drought stressed common bean after inoculation with tolerant native rhizobia in extensive fields. Agric. Ecosyst. Environ. 2016, 232, 119-128. [CrossRef]

28. Figueiredo, M.V.B.; Burity, H.A.; França, F.P. Water deficit stress effects on N2 fixation in cowpea inoculated with different Bradyrhizobium strains. Can. J. Plant Sci. 1998, 78, 577-582. [CrossRef]

29. Figueiredo, M.V.; Burity, H.A.; Martínez, C.; Chanway, C.P. Alleviation of drought stress in the common bean (Phaseolus vulgaris L.) by co-inoculation with Paenibacillus polymyxa and Rhizobium tropici. Appl. Soil Ecol. 2008, 40, 182-188. [CrossRef]

30. Bano, A.; Batool, R.; Dazzo, F. Adaptation of chickpea to desiccation stress is enhanced by symbiotic rhizobia. Symbiosis 2014, 50, 129-133. [CrossRef]

31. Franzini, V.I.; Azcón, R.; Méndes, F.L.; Aroca, R. Different interaction among Glomus and Rhizobium species on Phaseolus vulgaris and Zea mays plant growth, physiology and symbiotic development under moderate drought stress conditions. Plant Growth Regul. 2013, 70, 265-273. [CrossRef]

32. Mouradi, M.; Farissi, M.; Bouizgaren, A.; Makoudi, B.; Kabbadi, A.; Very, A.; Sentenac, H.; Qaddourya, A.; Ghoulam, C. Effects of water deficit on growth, nodulation and physiological and biochemical processes in Medicago sativa-rhizobia symbiotic association. Arid Land Res. Manag. 2016, 30, 193-208. [CrossRef]

33. Giller, K.E. Nitrogen Fixation in Tropical Cropping Systems, 2nd ed.; CABI Publishing: Wallingford, UK, 2001; pp. 253-270. [CrossRef]

34. Farquhar, G.D.; Richards, R.A. Isotopic Composition of Plant Carbon Correlates with Water-use Efficiency of Wheat Genotypes. Aust. J. Plant Physiol. 1984, 11, 539-552. [CrossRef]

35. Barbour, M.M. Stable oxygen isotope composition of plant tissue: A review. Funct. Plant Biol. 2007, 34, 83-94. [CrossRef]

36. Wang, C.; Wu, S.X.; Tankari, M.; Zhang, X.M.; Li, L.; Gong, D.Z.; Hao, W.P.; Zhang, Y.Q.; Mei, X.R.; Wang, Y.F.; et al. Stomatal aperture rather than nitrogen nutrition determined water use efficiency of tomato plants under nitrogen fertigation. Agric. Water Manag. 2018, 209, 94-101. [CrossRef]

37. Ninou, E.; Tsialtas, J.T.; Dordas, C.A.; Papakosta, D.K. Effect of irrigation on the relationships between leaf gas exchange related traits and yield in dwarf dry bean grown under Mediterranean conditions. Agric. Water Manag. 2013, 116, 235-241. [CrossRef]

38. Rivas, R.; Falcão, H.M.; Ribeiro, R.V.; Machado, E.C.; Pimentel, C.; Santos, M.G. Drought tolerance in cowpea species is driven by less sensitivity of leaf gas exchange to water deficit and rapid recovery of photosynthesis after rehydration. S. Afr. J. Bot. 2016, 103, 101-107. [CrossRef]

39. Maia, J.M.; de Macedo, C.E.C.; Voigt, E.L.; Freitas, J.B.S.; Silveira, J.A.G. Antioxidative enzymatic protection in leaves of two contrasting cowpea cultivars under salinity. Biol. Plant. 2010, 54, 159-163. [CrossRef]

40. Barbosa, M.A.M.; Lobato, A.K.D.S.; Viana, G.D.M.; Coelho, K.N.N.; Barbosa, J.R.S.; Da Costa, R.C.L.; Neto, C.F.D.O. Root contribution to water relations and shoot in two contrasting Vigna unguiculata cultivars subjected to water deficit and inoculation. Rom. Agric. Res. 2012, 30, 155-162.

41. Davies, W.J.; Wilkinson, S.; Loveys, B. Stomatal control by chemical signalling and the exploitation of this mechanism to increase water use efficiency in agriculture. New Phytol. 2008, 153, 449-460. [CrossRef] 
42. Man, D.; Bao, Y.X.; Han, L.B.; Zhang, X. Drought tolerance associated with proline and hormone metabolism in two tall fescue cultivars. HortScience 2011, 46, 1027-1032. [CrossRef]

43. Comstock, J.P. Hydraulic and chemical signalling in the control of stomatal conductance and transpriation. J. Exp. Bot. 2002, 53, 195-200. [CrossRef]

44. Ismail, A.M.; Hall, A.E.; Bray, E.A. Drought and pot size effects on transpiration efficiency and carbon-isotope discrimination of cowpea accessions and hybrids. Aust. J. Plant Physiol. 1994, 21, 23-35. [CrossRef]

45. Verbree, D.A.; Singh, B.B.; Payne, W.A. Role of gas exchange, leaf water status, and carbohydrate partitioning during the early vegetative stage on drought tolerance in cowpea. Crop Sci. 2014, 54, 770-778. [CrossRef]

46. Tairo, E.; Mtei, K.; Ndakidemi, P. Influence of Water Stress and Rhizobial Inoculation on the Accumulation of Chlorophyll in Phaseolus vulgaris (L.) Cultivars. Int. J. Plant Soil Sci. 2017, 15, 1-13. [CrossRef]

47. Ismail, A.M.; Hall, A.E. Correlation between water-use efficiency and carbon isotope discrimination in diverse cowpea genotypes and isogenic lines. Crop Sci. 1992, 32, 7-12. [CrossRef]

48. Tomás, M.; Medrano, H.; Pou, A.; Escalona, J.M.; Martorell, S.; Ribas-Carbó, M.; Flexas, J. Water-use efficiency in grapevine cultivars grown under controlled conditions: Effects of water stress at the leaf and whole-plant level. Aust. J. Grape Wine Res. 2012, 18, 164-172. [CrossRef]

49. Flanagan, L.B.; Farquhar, G.D. Variation in the carbon and oxygen isotope composition of plant biomass and its relationship to water-use efficiency at the leaf- and ecosystem-scales in a northern Great Plains grassland. Plant Cell Environ. 2014, 37, 425-438. [CrossRef]

50. Martin, B.; Thorstenson, Y.R. Stable Carbon Isotope Composition ( $813 \mathrm{C})$, Water Use Efficiency, and Biomass Productivity of Lycopersicon esculentum, Lycopersicon pennellii, and the F1 Hybrid. Plant Physiol. 1988, 88, 213-217. [CrossRef] [PubMed]

51. Wang, Y.; Zhang, X.; Liu, X.; Zhang, X.; Shao, L.; Sun, H.; Chen, S. The effects of nitrogen supply and water regime on instantaneous WUE, time-integrated WUE and carbon isotope discrimination in winter wheat. Field Crops Res. 2013, 144, 236-244. [CrossRef]

52. Ellsworth, P.Z.; Ellsworth, P.V.; Cousins, A.B. Relationship of leaf oxygen and carbon isotopic composition with transpiration efficiency in the C4 grasses Setaria viridis and Setaria Italica. J. Exp. Bot. 2017, 68, 3513-3528. [CrossRef]

53. Condon, A.G.; Richards, R.A.; Rebetzke, G.J.; Farquhar, G.D. Breeding for high water-use efficiency. J. Exp. Bot. 2004, 55, 2447-2460. [CrossRef]

54. Farquhar, G.D.; Barbour, M.M.; Henry, B.K. Interpretation of oxygen isotope composition of leaf material. In Stable Isotopes: Integration of Biological, Ecological and Geochemical Processes; Griffiths, H., Ed.; Bios Scientific Publishers: Oxoford, UK, 1998; pp. 27-48.

55. Scheidegger, Y.; Saurer, M.; Bahn, M.; Siegwolf, R. Linking stable oxygen and carbon isotopes with stomatal conductance and photosynthetic capacity: A conceptual model. Oecologia 2000, 125, 350-357. [CrossRef] [PubMed]

56. Barbour, M.M.; Fischer, R.A.; Sayre, K.D.; Farquhar, G.D. Oxygen isotope ratio of leaf and grain material correlates with stomatal conductance and grain yield in irrigated wheat. Aust. J. Plant Physiol. 2000, 27, 625-637. [CrossRef]

57. Grams, T.E.E.; Kozovits, A.R.; Häberle, K.H.; Matyssek, R.; Dawson, T.E. Combining $\delta^{13} \mathrm{C}$ and $\delta^{18} \mathrm{O}$ analyses to unravel competition, $\mathrm{CO}_{2}$ and $\mathrm{O}_{3}$ effects on the physiological performance of different-aged trees. Plantcell Environ. 2007, 30, 1023-1034.

58. Roden, J.S.; Farquhar, G.D. A controlled test of the dual-isotope approach for the interpretation of stable carbon and oxygen isotope ratio variation in tree rings. Tree Physiol. 2012, 32, 490-503. [CrossRef] [PubMed]

59. Mathu, S.; Herrmann, L.; Pypers, P.; Matiru, V.; Mwirichia, R.; Lesueur, D. Potential of indigenous bradyrhizobia versus commercial inoculants to improve cowpea (Vigna unguiculata L. walp.) and green gram (Vigna radiata L. wilczek.) yields in Kenya. Soil Sci. Plant Nutr. 2012, 58, 750-763. [CrossRef]

60. Aliyu, I.A.; Yusuf, A.A.; Abaidoo, R.C. Response of grain legumes to rhizobial inoculation in two savanna soils of Nigeria. Afr. J. Microbiol. Res. 2013, 15, 1332-1342. [CrossRef]

61. Ulzen, J.; Abaidoo, R.C.; Mensah, N.E.; Masso, C.; Abdelgadir, A.H. Bradyrhizobium Inoculants Enhance Grain Yields of Soybean and Cowpea in Northern Ghana. Front. Plant Sci. 2016, 7, 1-9. [CrossRef]

62. Diallo, A.T.; Samb, P.I.; Roy-Macauley, H. Water status and stomatal behaviour of cowpea, Vigna unguiculata (L.) Walp, plants inoculated with two Glomus species at low soil moisture levels. Eur. J. Soil Biol. 2001, 37, 187-196. [CrossRef] 
63. Sanginga, N.; Dashiell, K.; Okogun, J.A.; Thottappilly, G. Nitrogen fixation and N contribution by promiscuous nodulating soybeans in the southern Guinea savanna of Nigeria. Plant Soil 1997, 195, 257-266. [CrossRef]

64. Okogun, J.A.; Sanginga, N. Can introduced and indigenous rhizobia strains compete for nodule formation by promiscuous soybean in the moist savanna agroecological zone of Nigeria? Biol. Fertil. Soils 2003, 38, 26-31. [CrossRef]

65. Figueiredo, M.V.B.; Burity, H.A.; França, F.P. Alleviaion of water stress effects in cowpea by Bradyrhizobium spp. inoculation. Plant Soil 1999, 207, 67-75. [CrossRef]

66. Catroux, G.; Hartmann, A.; Revellin, C. Trends in rhizobial inoculant production and use. Plant Soil 2001, 230, 21-30. [CrossRef]

(C) 2019 by the authors. Licensee MDPI, Basel, Switzerland. This article is an open access article distributed under the terms and conditions of the Creative Commons Attribution (CC BY) license (http:/ / creativecommons.org/licenses/by/4.0/). 